\title{
Normal cerebellar glutamate dehydrogenase protein in spinocerebellar degeneration
}

\author{
ROGER N ROSENBERG,* CARL BANNER $\dagger$ \\ From the Department of Neurology, ${ }^{*}$ University of Texas Southwestern Medical Center at Dallas, Dallas, \\ Texas, and the Laboratory of Molecular Biology, $\uparrow$ National Institute of Neurological and Communicative \\ Disorders and Stroke, National Institutes of Health, Bethesda, Maryland, USA
}

SUMMARY Immunochemical analyses (Western blots) of cerebellar homogenates for glutamate dehydrogenase (GDH) from patients with spinocerebellar degeneration and control subjects were conducted. Four patients with autosomal dominant Joseph disease type of spinocerebellar degeneration, one patient with autosomal dominant olivopontocerebellar degeneration and four control subjects were studied. GDH was of the same molecular weight and amount in all patients and control subjects. These data together with normal GDH activity from these same homogenates published previously support the view that GDH is not involved in the pathogenesis of these types of dominantly inherited spinocerebellar degeneration.

The primary biochemical defect in autosomal dominant Joseph disease (JD) and olivopontocerebellar atrophy (OPCA) is not known. ${ }^{1-6} \mathrm{~A}$ deficiency in fibroblast and leukocyte glutamate dehydrogenase (GDH) (EC 1.4.1.3) specific activity has been reported in autosomal recessive and autosomal dominant forms of OPCA. ${ }^{7-15}$ The protein content of leukocyte GDH was reported to be decreased in four of 14 patients studied with spinocerebellar degeneration (SCD) and the reduction in the protein content was proportional to that in the enzyme activity. ${ }^{16}$ We have reported normal mitochondrial and cytosolic GDH activity in cerebellar and cerebral cortex from OPCA and JD patients compared to control subjects. ${ }^{17}$ We follow up here on those studies by reporting the Western blot analysis of GDH in the cerebellum from JD and OPCA patients and control subjects.

\section{Materials and methods}

\section{Patient material}

Control brain samples were obtained from the Dallas County Medical Examiner's Office through the courtesy of Dr Charles Petty, Chief Medical Examiner. Control patient 5

Address for reprint requests: Roger N Rosenberg, M.D., Professor and Chairman, Department of Neurology, University of Texas Southwestern Medical Center at Dallas, 5323 Harry Hines Blvd, Dallas, Texas, USA.

Received 23 September 1988. Accepted 18 November 1988 (numbered to correlate with the fig) was a 23 year old man who died of a gun shot wound. Control patient 6 was a 48 year old man who died in a car accident. Control patient 7 was a 33 year old man who died of a myocardial infarction. Control patient 8 was a 37 year old man who died of a gun shot wound. All brains were removed in the medical examiner's office and frozen within 10 hours after death, and the bodies were refrigerated to $4^{\circ} \mathrm{C}$ within 2 hours after death.

Joseph disease brains were removed in local hospitals by attending pathologists within 5 hours after death. The bodies were refrigerated within 2 hours after death to $4^{\circ} \mathrm{C}$; brain samples were frozen immediately at the time of necropsy.

JD patient 1 was a 43 year old man with disease for 15 years. JD patient 2 was a 58 year old man with disease for at least 20 years. JD patient 3 was a 60 year old man with disease for 20 years. JD patient 4 was a 75 year old man with disease for at least 10 years. OPCA patient 1 was a 55 year old man with symptoms for 15 years.

The brain was sent through the courtesy of Dr Larry Schut, Minneapolis, Minnesota. The patient was examined by Dr Schut and was a member of an established family with autosomal dominant OPCA.

All brain samples from contol, JD, and OPCA patients were initially frozen on dry ice and then stored at $-70^{\circ} \mathrm{C}$.

\section{Immunoblot methods}

The tissue samples were homogenised on ice in $0.0625 \mathrm{M}$ Tris, pH 6.8, 2\% SDS, $10 \%$ glycerol, $5 \%$ 2-mercaptoethanol and then boiled for 3 minutes. Thirty $\mu \mathrm{g}$ of protein from each lysate was subjected to SDS-polyacrylamide gel electrophoresis. Protein concentration was determined by the Lowry assay after precipitation with trichloroacetic acid. ${ }^{18}$ The amount of protein applied to the gel was chosen so as to 


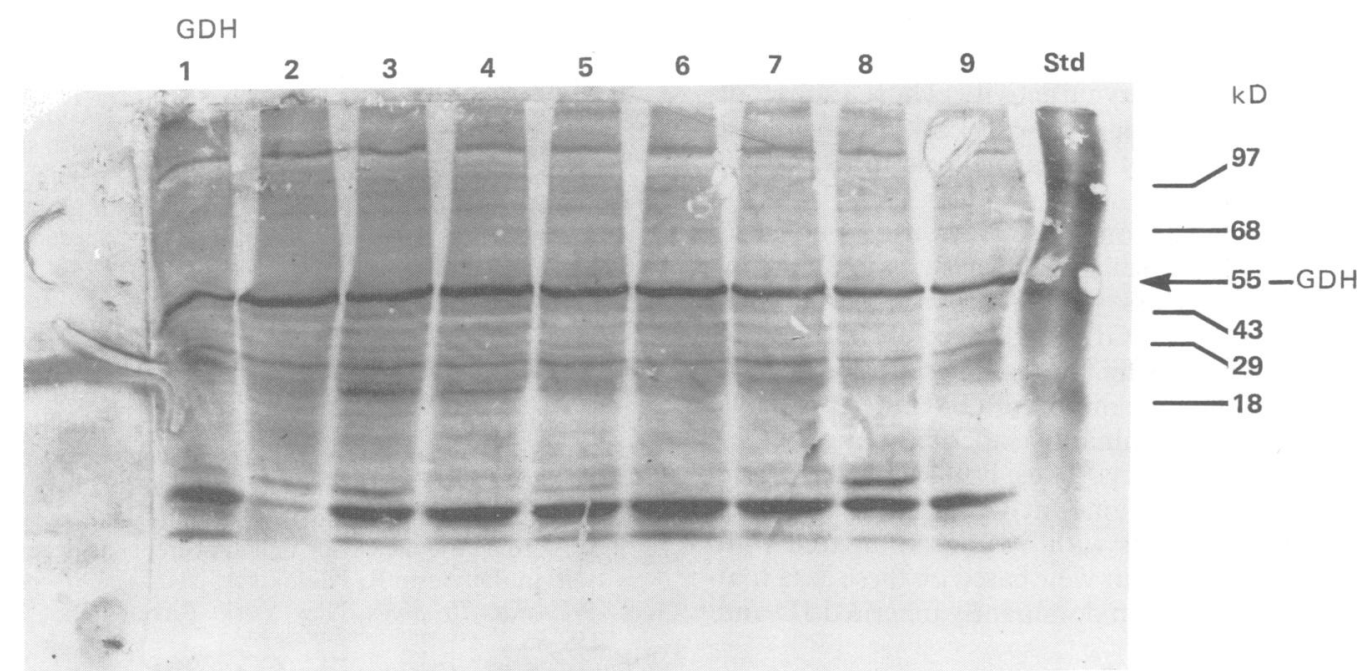

Fig Western immunoblot analysis for GDH protein from patient and control subject cerebellar homogenates. Lanes 1-4 are JD patients; lanes 5-8 are control subjects; lane 9 is an OPCA patient. Numbers correspond to patient number used in the Materials and Methods Section. Std refers to molecular weight standards. GDH is $55 k D$.

be within the proportional range of alkaline phosphatase reactivity (data not shown). The proteins were electroblotted from the gel to a nitrocellulose filter. ${ }^{19}$ Monoclonal antiGDH antibody was a kind gift of Dr A J Beitz. The nitrocellulose filters were incubated with this antibody as previously described by Wenthold et al ${ }^{20}$ Detection of bound antibodies was by alkaline phosphatase conjugated antimouse IgG (Promega).

\section{Results}

GDH was identified by Western immunoblotting from four patients with JD, one patient with OPCA, and four control subjects. It had the same molecular weight $(55 \mathrm{kD})$ in all subjects and was present equally in these cerebellar homogenates within the range of variability among the controls (fig).

\section{Discussion}

A deficiency in GDH was first described in patient fibroblast cultures by Plaitakis et $a l^{7}$ in a patient with autosomal recessive OPCA. Leukocytes from that patient also had decreased GDH activity. ${ }^{10}$ Subsequently, Plaitakis et al ${ }^{10} 11$ made similar observations in 88 other patients with different neurologic disorders. Twelve patients with progressive multiple-system atrophic disorders had partial deficiency of GDH ( $52 \%$ of control level). Seven of those patients with GDH deficiency had autosomal recessive patterns of inheritance, and five were sporadic. They found that it was essential to fractionate GDH; leukocyte GDH deficiency was limited to the particulate, heat-labile component (bound to a mitochondrial membrane) and was not found in the soluble, heat-stable component. They suggested that the magnitude of the decrease in the heat-labile GDH to $8 \%$ of control level was consistent with a recessively inherited primary enzymatic defect, and that a GDH isozyme defect was the primary mutation. ${ }^{1011}$

Plaitakis found normal GDH activity in autosomal dominant OPCA. However, Duvoisin et al $^{1314}$ found low leukocyte GDH in presumably dominantly inherited OPCA, with patients having $38 \%$ of normal GDH leukocyte specific activity. Finocchiaro et al ${ }^{15}$ studied GDH in leukocytes in 11 patients with dominantly inherited OPCA, in three patients with recessively inherited OPCA, and in one sporadic case. Leukocyte values were reduced to $68 \%$ of control and reduced to $46 \%$ in muscle mitochondria compared to control in the dominantly inherited OPCA patients. They found that an oral glutamate loading test produced higher plasma glutamate levels in patients compared with controls. They concluded that a subset of OPCA patients had a defect in mitochondrial glutamate metabolism. ${ }^{15}$

We utilised cerebral cortical and cerebellar cortical frozen necropsy samples obtained from JD, OPCA, and control patients for GDH assays. There was no statistically significant difference in specific activity of mitochondrial or cytoplasmic GDH in OPCA or JD samples compared with control subject samples. ${ }^{17}$

Recently, Kajiyama et al reported decreased GDH protein in leukocytes in patients with SCD or atypical Parkinsonism. ${ }^{16}$ The protein content of leukocyte 
GDH was decreased in only four patients of 14 studied and the reduction in the protein content was proportional to that in the enzyme activity. Thus, a subset of patients with SCD or atypical Parkinsonism had reduced GDH activity and protein as measured by radioimmunoassay.

We followed up on our previously published observations on cerebellar GDH activity in $\mathrm{SCD}^{17}$ by immunochemically assaying (Western immunoblots) patient and control GDH from cerebellar homotenates. As seen in the fig, these studies showed normal molecular weight and amount of GDH in JD patients and in an OPCA dominantly inherited patient compared to control subjects. Thus, both cerebellar GDH activity ${ }^{17}$ and protein amount were within a normal range in these patients with SCD as compared with control subjects. It is our view based on these data that GDH is not involved in dominantly inherited JD and OPCA.

We express our gratitude to Dr A J Beitz for monoclonal anti-GDH antisera and to Mrs Sally Gagne for technical assistance.

\section{References}

1 Morrison M, Rosenberg R. Specific messenger RNA changes in Joseph disease cerebella. Ann Neurol 1983; 14:73-9.

2 Rosenberg R. Molecular genetics, recombinant DNA techniques and genetic neurological disease. Ann Neurol 1984;15:511-20.

3 Rosenberg R. Dominant ataxias. In: Kety S, Rowland L, Sidman R, Mattaysse S, eds. Genetics of Neurological and Psychiatric Disorders. New York: Raven Press, 1983:195-213.

4 Rosenberg R. Joseph's disease. In: Kark P, Rosenberg R, Schut $\mathbf{L}$, eds. The Inherited Ataxias. New York: Raven Press, 1978:33-57.

5 Rosenberg R, Ivy N, Kirkpatrick J, Bay C, Nyhan W, Baskin F. Joseph disease and Huntington disease: protein patterns in fibroblasts and brain. Neurology 1981;31:1003-14.

6 Rosenberg R, Nyhan W, Bay C, et al. Autosomal dominant striationigral degeneration: a clinical, pathologic and biochemical study of a new genetic disorder. Neurology 1976;26:703-14.

7 Plaitakis A, Nicklas W, Desnick R. Glutamate dehydrogenase deficiency in three patients with spinocerebellar ataxia: a new enzymatic defect? Trans Am Neurol Assoc 1979;104:54-7.

8 Plaitakis A, Nicklas W, Desnick R. Glutamate dehydrogenase deficiency in three patients with spinocerebellar syndrome. Ann Neurol 1980;7:297-303.

9 Plaitakis A, Berl S, Yahr M. Abnormal glutamate metabolism in an adult-onset degenerative neurological disorder. Science 1982;216:193-6.

10 Plaitakis A, Berl S, Yahr M. Neurological disorders associated with deficiency of glutamate dehydrogenase. Ann Neurol 1984;15:144-53.

11 Plaitakis A. Abnormal metabolism of neuroexcitatory amino acids in olivopontocerebellar atrophy. In: Duvoisin R, Plaitakis A, eds. The Olivopontocerebellar Atrophies. New York: Raven Press, 1984:225-43.

12 Maruyama S, Yamaguchi T. Glutamate and pyruvate dehydrogenase deficiency in spinocerebellar degeneration. In: Duvoisin R, Plaitakis A, eds. The Olivopontocerebellar Atrophies. New York: Raven Press, 1984: 255-65.

13 Duvoisin R, Chokroverty $S$. Clinical expression of glutamate dehydrogenase deficiency. In: Duvoisin $\mathbf{R}$, Plaitakis A, eds. The Olivopontocerebellar Atrophies. New York: Raven Press, 1984:267-79.

14 Duvoisin R, Chokroverty S, Lepore F, Nicklas W. Glutamate dehydrogenase deficiency in patients with olivopontocerebellar atrophy. Neurology 1983;33: 1322-6.

15 Finocchiaro G, Taroni F, Didonato S. Glutamate dehydrogenase activity in olivopontocerebellar atrophies. Neurology 1986;36:550-3.

16 Kajiyama K, Ueno S, Tatsumi T, Yorifuji S, Takahashi M, Tarui S. Decreased glutamate dehydrogenase protein in spinocerebellar degeneration. J Neurol Neurosurg Psychiatry 1988;51:1078-80.

17 Grossman A, Rosenberg R, Warmoth L. Glutamate and malate dehydrogenase activities in Joseph disease and olivopontocerebellar atrophy. Neurology 1987;37: 106-11.

18 Lowry O, Roseborough N, Farr A, Randall R. Protein measurement with the folin phenol reagent. $J$ Biol Chem 1951;193:265.

19 Towbin H, Staehelin T, Gordon J. Electrophoretic transfer of proteins from polyacrylamide gels to nitrocellulose sheets; procedures and some applications. Proc Natl Acad Sci 1979;76:4350-4.

20 Wenthold R, Altschuler R, Skaggs K, Reeks K. Immunocytochemical characterization of glutamate dehydrogenase in the cerebellum of rat. $J$ Neurochem 1987;48:636-43. 